\title{
Applying Comprehensible Input and Culture Input Methodology to Inspire College Students' Learning Motivation
}

\author{
Yang Liu \\ Changchun University of Science and Technology, China
}

\begin{abstract}
Motivation is a non-intellectual and key factor to the success or failure of English learning. The stronger motivation one has, the better English proficiency he/she will get. There is no exception of college students, who need to build up motivation to learn English better and consistently. This thesis proposes two teaching methodologies based on Krashen's Input theory and theories of cross-culture communication, which are comprehensible input and culture input methodologies, aiming to assist college students to establish strong and consistent motivation in English learning.
\end{abstract}

Index Terms-motivation, college English, comprehensible input methodology, culture input methodology

\section{INTRODUCTION}

According to college English teaching status analysis, how to teach students to learn efficiently with the limited time and limited resources is the most important part of College English Teaching. If the teacher uses the right method in class the students would be interested in English language and would be full of confidence. Teachers' relaxed and happy work feelings in learning will certainly arouse the appropriate enthusiasm and inspire students' learning motivation, so that teachers and students can cooperate joyfully. For a long time, domestic and foreign language learning researchers conduct foreign language learning motivation as wide range of research, get forward a wealth of research results, put forward a number of foreign language learning motivation theoretical model. However, in recent years, some of the domestic researchers are aiming at Chinese students' English learning motivation, a large number of research results have fully proved the important status of the foreign language learning motivation.

Motivation is agreed as the most important element in so many individual factors of language learning right now, it is a kind of drive and momentum which impulses learners to study the target language consistently and efficiently. English pedagogic theorists, teachers and researchers have carried out multitudes of studies, reflections, practices and explorations on approaches and strategies of college students. It's vital for college English teachers to design each English class language input more systematically and creatively to attract students' attention and stimulate their interest in English learning and consequently establish students' consistent motivation in English learning. This paper intends to enumerate some language input strategies and methods to motivate and train learning motivations in class to stimulate students' motivation and make it to be maintained, and then learners' study efficiency can be improved. Therefore the two language input methodology is comprehensively discussed in the following thesis.

This thesis is composed of four parts. The first part is the introduction part, which intends to give a clear picture of the thesis illustration. The second part is the motivation theory, especially indirect language motivation theory which is the main problem the thesis discusses and aims to solve; in the third part, comprehensible input and culture input language teaching methodologies are presented, which are the rational ways for the motivation inspiration and cultivation of the English learners, therefore it's the problem- solving and central part of the thesis; finally, the conclusion of the thesis is given in part four which is about to advocate the applying of comprehensible input and culture input language teaching methodologies in college English teaching practice.

\section{MOTIVATION THEORY}

Motivation is the internal driving force of human behavior (a motivation is to achieve a certain objective of the internal driving force), its meaning is mankind's specific requirements. Being interested in something is one of its important performance characteristics, and the things its own interest is an important motivation generated incentives.

\section{Conception and Necessity of Motivation}

\section{Learning Motivation}

Motivation to learn is the need to stimulate people to directly promote the study of the internal driving force. Inner motivation is a potential activities, can't be directly observed but its content varied and difficult to make reference to. The same motivation is not exactly the same form of expression. Because of the potential motivations and the complexity of its content, the motivation to learn can be divided into direct and indirect categories.

\section{Direct Motivation}


Direct motivation to learn is that the learner has a direct interest in the study or the pursuit of short-term effects caused by the motivation. Such as for the sake of high scores, as a subject of interest or for teachers' good impression and so on. These are more specific, but they are not lasting. Childhood motivation to learn is more of such.

\section{Indirect Motivation}

Indirect motivation to learn is closely related to social demands and the vision of motivations, such as to explore the universe and the mysteries of astronomy professional learning, to reduce human suffering to learn medical science, and for the benefit of the nation and the transfer of Social Sciences, in order to strengthen exchanges the volunteers learn foreign languages, and so on. Such a vision of motivation will not be met in the short term, once established it will be relatively stable and lasting. Young people often have the motivation to increase with age into the indirect tendency of motivation.

As China's reform and opening up policy in the deep exchanges with other countries more and more frequently, we should learn from foreign culture and language to exchange with foreigners, foreign language proficiency is a necessary condition. But the motivation of a certain part of college students is direct, and to a considerable part of the students only indirectly.

The traditional English teaching in China is mainly focusing on teaching knowledge. Teachers spend most time in explaining words, grammar and analyzing sentence structure. Thus, teachers are the center of class, while students are thrown into a passive situation, which make students lose the opportunity of practice and the passion for learning. According to the recent statistics, more than $85 \%$ of students think that teachers are the center of class. During the learning processes of listening and speaking, students need to react to language with a high-speed and have no time to translate English into Chinese. In order to gain the ability to quick react, students should practice more and develop a good habit of thinking in English. Students should also develop a better understanding of the cultural differences because the differences between cultures and different language habits are also obstacles for students to improve their abilities to listen and speak. Hence, increasing the understanding of cultures of different English speaking countries is very important for students.

\section{Cultivate And Inspire Students’ Motivation to Learn EnGlish}

The ultimate aim of learning motivation study is to make the theory used in educational practice, so that teachers can be more conscious and more effective to train students to learn English enthusiastically, to improve the quality of education quickly. To cultivate and inspire the motivation to learn is in the course of study which mainly relies on teachers' teaching content, teaching methods and teaching organization. The following part is focused on the teaching methods based on Krashen's Input Hypothesis and cross-cultural communication theories.

\section{A. "Input” Theories and Culture Background}

The success in foreign language learning depends on many factors, among which the "input" theory is very important. Input affects the achievement of foreign language teaching and acquisition. Comprehensible input and cultural background teaching are the efficient input methods of foreign language teaching.

\section{1. "Input" Theories and Second Language Acquisition}

In foreign Language teaching and research field, Krashen's "input" theory has been occupied an extremely important position in Second Language Acquisition, his theory support that: "comprehensible input" is the key for language acquisition. When students come into the new language materials, they will maneuver the enthusiasm of learning in order to understand the content at the current level or with the help of the relevant context. In this way, "Input" enter into the understandable level and can be acquired by learners, thus they will raise the higher level of language learning. Ellis also thinks that the Second Language Acquisition refers to "The progress of acquiring a foreign language other than mother tongue under the natural or the guidance of a awareness of learning or unconsciousness." Being affected by these theories, the key point of foreign languages teaching and research focus gradually from the "how to teach" to "how to learn". Apparently, "Input" requires not only a large quantity but also not very difficult language input to understand to make the learners acquire second language successfully. To be useful to the learner, the input must be neither too difficult to understand nor too easy. This is conceptualized by Krashen in terms of the learner's current level, called $i$, and the level that the learner will get to next, called $i+1$. For the learner to progress rather than remain static, the input has always to be slightly beyond the level at which he or she is completely at home; the gap between the learner's $i$ and the $i+1$ that he or she needs is bridged by information drawn from the situation and from the learner's previous experience. (Xu, 2011)

\section{Apply "Input" Theories in English Class}

In foreign language teaching, teachers should be certain in which English level students are located and then try to make students receive neither too difficult nor too easy materials to understand. Whereas the fact in Chinese college English teaching is that, students' English level verified greatly from very high level; high level; just-so-so level to low level and quite low level, and each level of students are commonly seen in the definite English classroom and they are to receive the definite teacher's English presentation input while using the definite intensive reading text book, therefore, the language input they are to receive is definitely same. This violates the $i+1$ language acquisition principle to some extent. Some lower English level students have no ability to understand what their teacher is presenting in class and 
they feel frustrated and have very low motivation in learning English, meanwhile, to some other students with very high English level they sometimes feel too proud that they seem to know everything of teacher's presentation or they've lagged their classmates behind a long distance, that is to say, this group of students may still have low motivation in English learning and not concentrate on what is lecturing in English class either.

To solve this kind of motivation problem teachers should take measures to assist students to be in the same or nearly the same language preparing situations, that is to say they should have a general understanding of the discourse material to be presented before each class. Assigning pre-class input homework to students of different English level is a reasonable way to orientate them to approach $\mathrm{i}+1$ class presentation. The pre - class input should involve aspects of both teachers and students. For one thing, teachers' pre - class input should cover, if in intensive reading class, 1). Background presentation of the discourse. 2) Making summary and brief introduction and analysis of the discourse. 3).Offering some questions of thought provoking related to the discourse for students to think of. Teachers' efforts above aim to make students have a clear picture of the discourse setting and the general impression of the discourse, which is one way to get teacher's presentation comprehensible to most students, therefore to enhance students' English learning motivation. While if in oral or listening English class, teachers should assign students to do some oral practice or listening homework before class, which is one way to make preparation for class language input and make it comprehensible. For another, each student should get involved if in intensive reading class: 1) Getting translation of the discourse to understand meaning of each sentence. 2) Listening to the record of discourse to get impact of native-speaker's articulation. 3) Replying questions proposed by the teacher. 4) Collecting input materials to develop interest in learning English. The pre-class input is supposed as necessary knowledge preparation for the class presentation now that while teachers present the class they are about to be in the $\mathrm{i}+1$ situation to enjoy the English class and it's helpful to cultivate students' self-study habit which is to give students more confidence and motivation confronting the presentation of English class. In each type of class, teachers might let students collect relevant input materials by reading other books or surfing the internet, which is another way to motivate students' interest in involving English learning.

While teaching in English class, teachers should fully understand the students, teachers should consider the differences of students personality and characteristics, hence apply different approaches targeting for teaching, training and improving their respective proficiencies. Such as to export-oriented character of students, they are lively and bold, therefore rapid response "principle of exact learning," should be used for such students in the protection of their enthusiasm, at the same time, the high demand for them is right. To the character of slow, slow reaction students, teachers should use "principle of incentives" focused on training them to speak, which is teachers' good habit and is to encourage students to question their courage to speak. This is one of the most important way to solve the problems in oral expression.

There are a lot of data show that, if teacher use the proper method, students will be on English interest and confidence. Teachers teaching in the relaxed atmosphere in class, learning will certainly arouse the appropriate enthusiasm and inspire students' motivation to learn, thus make the teachers and students cooperate pleasantly and there will be a good harvest.(From: www.8ttt8.com)

\section{B. Culture Knowledge and Students' Learning Motivation}

Language and culture have a close relation.. "Language is the carrier of culture and culture is the content of language. There is no language without culture content." "As a mirror of culture, language is strongly influenced and shaped by culture". In history they evolved together and have been mutually dependent. They need understanding each other. In the broadest sense, language is the symbolic representation of a people, and it comprises their historical and cultural backgrounds as well as their approach to life and their ways of living and thinking. Following the definitions of sociologists and anthropologists, the term culture "refers to the total pattern of beliefs, customs, institutions, objects, and techniques that characterize the life of a human community." Language is the most important one of culture and language also reflects culture. And at the same time, culture influenced and shaped language. Cultures are different, so languages are different. It is proved that teaching students of cross- culture communication is a trigger to arouse their desire for culture knowledge.

\section{Culture Knowledge in English Teaching}

It is natural that cross-cultural communication is not always easy with differences in cultures and in languages. So, teaching English means more than merely teaching students the vocabulary, grammars and structures. It also means teaching them how to know the English culture. Learners should be informed how native speakers of English see the world and how the English language reflects the minds, customs, and behavior of their society.

\section{Principles and Approaches}

"There are three principles to guide the cultural introduction: (1) relevant principles (2) comparative principles (3) appropriate principles".( www.8ttt8.com)

Relevant principle demands the culture content introduced should be closely related to the language the students learn. In addition, culture content should be useful for daily communication. In this way, students will not think the relationship between language and culture is too abstract and difficult to understand. With the guiding of the relevant principle, teachers can better motivate students' interest in language and its culture.

For the Chinese students, the cultural difference and background information is the biggest barrier for them to master 
English and communicate successfully with native speakers. Cultural differences between different cultures can greatly motivate students' interest in learning. Therefore, in language teaching, teachers should stick to the comparative principle, and introduce some cultural difference between target language and native language. The students can avoid some mistakes when they communicate with native speakers for the shortage of cultural knowledge.

Appropriate principle requests that teachers should consider students' ability in acceptation and introduce cultural knowledge according to the teaching task and purpose of learning. The teacher should explain and help students overcome their problems in an appropriate way when students encounter cultural barrier.

Teachers usually pay attention to communicative competence, while making cultural knowledge subsidiary in college English teaching practice. Background information occupies a vital position in improving students' language ability although cultural knowledge does not affect communication directly. In our English teaching materials, no matter it is intensive reading or extensive reading, what is selected in English textbooks is mainly from American/British newspaper, magazine and literature articles on aspects of American/British culture. While reading those materials, students are doing two kinds of activities: (1) Check the inference from the meaning of words. (2) infer the meaning of the text from its background information. Chinese and English belong to two different cultures. These two languages reflect their own culture. Some students have a good command of words and syntax, but they cannot understand the real meaning of the text for the shortage of related background information. In college English books, there are usually two reading texts in each unit, including geography, religion, history, system, customs and eating habits of English-speaking countries. In the process of teaching, in order to improve students' reading comprehension ability, language and communicative competence, the teacher should try to discover cultural background.

There are many cultural-loaded words in reading materials. Words are the most dynamic part in language and have rich cultural connotation. There will be misunderstanding if students only know the literal meaning of those words and don't know the difference in English-speaking countries. In English teaching, the teacher should explain the cultural meaning of these English words, which will not only broaden students' vision, but help them have a better understanding of cultural difference.

\section{Students' Basic Skills are Related to the Cultural Knowledge}

For example, when students are doing listening exercises, they may hear some easy dialogues. But he may make some mistakes, if students do not know some cultural information about western countries. The aim of listening is to exchange information and understand the speaker's real meaning in words successfully. Sometimes the learner only catches the denotation of the words, but can not consider the most important part, which is the contextual meaning of words and sentences.

Reading and writing English materials inevitably convey western culture. The students' lack of cultural background knowledge often hinders their comprehension in reading. In Chinese, we mean pornographic by the word “黄”, but in English , "blue" is used instead of "yellow". If we do not know, we will not understand what "blue film" or "blue video tapes" mean though the words are easy. This illustrates that words' connotations is the result of cultural impact on language. So more attention should be paid to cultural background in learning idioms and literary works, otherwise, we cannot understand the implication of words and the passages correctly.

The differences between the Chinese and western modes of thinking plays an important part in writing. We Chinese are accustomed to thinking in a spiral way, while the English people and Americans in a linear way. This different way of thinking often leads to misunderstanding. Sometimes a student's composition is good in terms of grammar and logic, but when a foreigner reads it, he or she may misunderstand the real meaning of the sentences.

Unless the students understand the cultural background, they cannot finish their exercises accurately. It's evidently wrong to interpret things in foreign languages in the same way as in our mother tongue. To some extent, students' cultural awareness influences the achievement of English teaching goal. Therefore, it is importance to take for cultural background knowledge as one of the contents in the whole process of English teaching so as to help students to have a good command of necessary cultural knowledge.

\section{Presentation of Culture Knowledge}

Presentation of cultural knowledge can benefit English teaching in at least three ways: (1) It can cultivate students' thinking. Presentation of cultural knowledge can help students get to know politics, economy, thoughts, and ideas of English-speaking countries and nationalities. They may get to understand the psychology and code of thinking of English-speaking people with general cultural knowledge. This is good for cultivating students' thinking and also a great help for them to think in English. (2)It can promote the study of our own culture. By means of learning the culture of English-speaking countries, students will deepen their realization about our own culture. The Chinese should have a good command in understanding of the Chinese culture, but in fact, many students of language know little about our own culture. The contrast between the Chinese and the western cultures will motivate the students to learn more English. Chinese people are curious about the culture of English-speaking countries, but they can get it only through reading plenty of materials in Chinese. Teachers should make good use of the motive to arouse students' interest in English learning. (3) It can develop students' awareness of cultural difference and help them form a good study habit. Usually students focus on language itself, but neglect the culture effect on language in English learning. They fail to notice that culture gives language special connotation and determines the use of it. Students can develop their sensitivity to cultural difference and gradually learn to catch cultural information themselves through cultural knowledge acquisition. They 
will also broaden their range of cultural knowledge, enhance their cultural absorption ability and improve their ability to use the English language.

\section{Develop Cultural Activities in Classroom}

The classroom is the most important place to cultivate students' cultural awareness. The teacher can organize group discussion, pair work and role-play except for explaining some necessary language points. The static language materials become vivid and lively in this way.

For example, some foods like pudding, turkey, salad, hamburgers are peculiar in western culture. Teachers can bring some pictures and objects to students, and the effect will be better. They will have a better understanding about western food and its dietetic culture.

Teachers can also have their students read some chosen materials related to their language teaching. For example, in Experiencing English Book3 Unit2-Nobile Prize Winners, the teacher can introduce four great scientists in class. All of whom had won Nobel Prizes. Madam Curie was the first women in the world who had won two Nobel Prizes. Many students know Nobel Prize, but some of them do not know clearly about its detailed information. The teacher can find out some related materials for students. The students will learn the language but also understand its culture.

Just as an educationalist says, "Tell me, I will forget. Show me, I may remember. Involve me, I will understand."The activities are beneficial to cultivate students' cultural awareness.

Culture has great impact on language. Lack of cultural background knowledge is the major cause of students' poor English, and is the most neglected factor in English teaching in China. By applying these practical strategies appropriately, English teachers are sure to help students enrich their cultural knowledge, to foster students' cultural competence and thus improve the results of English teaching. (From: http://www.8ttt8.com/lun/w42785.htm, 2013.6)

\section{CONCLUSION}

Motivation is the most important aspect of affecting foreign language learning, and it is also one of the most initiative factors. If one has high motivation, he or she has more chances to succeed. In foreign language teaching, teachers should motivate and train students learning motivation through many methods such as providing students with comprehensible input and cultural background input, teach students in accordance of their aptitude, interactive teaching and so on. To those learners who are lacking in motivation, teachers could not hurry too much. Give them initiative feedback for their endeavor and stimulate their extrinsic motivation in order to let them enjoy learning. In the process of this, their intrinsic motivation can be stimulated and improved. Once learners have strong learning motivation, they would put their potentials into practice as possible as they can, the learning efficiency naturally can be improved at high bound. (Huang Qian., 2012)

\section{REFERENCES}

[1] Vivan Cook. (2000.10). Linguistics and Second Language Acquisition. Foreign Language Teaching and Research Press, Macmillan Publishers Ltd.

[2] Bernard Spolsky. (2000). Conditions for second Language Learning. Shanghai Foreign Language Education Press, Shanghai

[3] Dai Manchun. (2000). Affective factors and their definitions- Review of Affect in Language Learning. Foreign Language Teaching and Researching. 6/32: 470-474.

[4] Diane Larsen - Freeman, Michael H. Long. (2006). An Introduction to Second Language Acquisition. Foreign Language Teaching and Research Press.

[5] Douglas L.Medin. (2001). The Psychology of Learning and Motivation. California: Academic Press.

[6] Elaine Tarone \& George Yule. (2000). Focus on the Language Learner. Shanghai Foreign Language Education Press; Shanghai.

[7] Gao Yihong, Cheng Ying, Zhao Yuan \& Zhou Yan. (2003). English Learning and Changes in Self- identity: A quantitative investigation on Chinese. Foreign Language Teaching and Research. 35/2: 132- 139.

[8] Guo Yali. (2003). How can teachers positively affect students' motivation? Teaching English in China. 26/1: 45-48.

[9] Hao Mei \& Hao Ruoping. (2001). Research on the relationship between English achievement and achievement motivation as well as anxiety state. Foreign Language Teaching and Research. 33/2: 112-116.

[10] H.D Brown. (2007.4) Principles of language Learning and Teaching Foreign Language Teaching and Research Press, Beijing.

[11] Herbert W.Seliger. (2007.3). Second Language Research Methods Shanghai Foreign Language Education Press; Shanghai.

[12] Hu Hongyan. (2003). The Influence of Anxiety and Self- Confidence on English Learning Teaching English in China. 26/1:36-41.

[13] Fang Xu. (19139020, 20110201). The Priority of Listening Comprehension over Speaking in the Language Acquisition Process, International Education Studies.

[14] Huang Qian. (2012). Action Research on Motivation in English Reading, Theory and Practice in Language Studies.

[15] Malik, Muhammad Asghar; Shah, Syed Kazim and Mahmood, Rashid. (2013). The Role of Linguistic Devices in Representing Ethnicity in The Kite Runner, International Journal of Linguistics (IJL).

[16] www.8ttt8.com.

[17] czytanki.net.

[18] www.zlunwen.com.

[19] czytanki.net. 
Yang Liu was born in Jilin, China in 1978. She received her master degree in linguistics from Changchun University of Science and Technology, China in 2007.

She is currently a lectorate in the School of Foreign Languages, Changchun University of Science and Technology; Changchun, China. Her research interests include psycholinguistics and inter-cultural communication. 